\title{
CARACTERIZAÇÃO DA ARGAMASSA DE ASSENTAMENTO DO MOSTEIRINHO DA IRMANDADE DE SÃO FRANCISCO EM PAUDALHO-PE
}

\author{
MARÍLIA LOPES DE SOUZA \\ Universidade Federal de Pernabuco (UFPE), Recife, Pernanbuco, Brasil \\ ARNALDO MANOEL PEREIRA CARNEIRO \\ Universidade Federal de Pernabuco (UFPE), Recife, Pernanbuco, Brasil \\ DOI: http://dx.doi.org.br/10.11606/issn.1980-4466.v0i19p164-186
}

\section{RESUMO}

Este trabalho apresenta um estudo realizado no Mosteirinho da Irmandade de São Francisco, um convento franciscano abandonado em Paudalho, município de Pernambuco. Foram realizadas a caracterização das argamassas de assentamento encontradas nesse edifício e a caracterização das areias encontradas próximo à construção, a fim de se fazer uma análise comparativa entre os compostos e se ter maior conhecimento acerca dos materiais utilizados. As amostras de argamassa foram submetidas a ensaios de granulometria por peneiramento, classificação petrográfica dos grãos, análises térmicas (ATG, DTG, ATD), fluorescência de raios X (FRX), difratometria de raios $\mathrm{X}(\mathrm{DRX})$ e microscopia, incluindo análise petrográfica e microscopia eletrônica de varredura (MEV). As amostras de areia foram submetidas a ensaio de distribuição granulométrica, classificação petrográfica dos grãos e microscopia óptica. Pelos ensaios realizados, verificou-se que as amostras de argamassa das paredes internas do edifício são compostas de barro, não tendo sido utilizada cal como aglomerante, enquanto a parede externa foi construída utilizando argamassa mista de barro e cal. As amostras de areia de rio possuem grande quantidade de fragmentos de conchas, e apresentam semelhança com o agregado de apenas umas das amostras analisadas. Isso é um indício de que a areia da região pode ter sido utilizada em pelo menos uma das fases de construção do edifício.

\section{PALAVRAS-CHAVE}

Argamassas históricas. Caracterização de argamassas. Patrimônio construído. 


\section{CHARACTERIZATION OF BEDDING MORTAR FROM THE MOSTEIRINHO DA IRMANDADE DE SÃO FRANCISCO, AT PAUDALHO, PERNAMBUCO, BRAZIL}

\section{MARÍLIA LOPES DE SOUZA}

Universidade Federal de Pernabuco (UFPE), Recife, Pernanbuco, Brasil ARNALDO MANOEL PEREIRA CARNEIRO

Universidade Federal de Pernabuco (UFPE), Recife, Pernanbuco, Brasil

DOI: http://dx.doi.org.br/10.11606/issn.1980-4466.v0i19p164-186

\section{ABSTRACT}

This work presents the study carried out at Mosteirinho da Irmandade de São Francisco, an abandoned Franciscan monastery in Paudalho, Pernambuco, in the northeast of Brazil. Bedding mortars found in the building were characterized and compared to sand samples collected near the building in order to better understand the materials used in its construction. Mortar samples went through granulometric analysis, thermogravimetric analysis, $\mathrm{X}$-ray fluorescence (XRF), X-ray diffractometry (XRD) and microscopy, including petrographic analysis and scanning electron microscopy (SEM). Sand samples went through granulometric analysis, petrographic classification of the grains and petrographic analysis. From the results, it is possible to conclude that the masonry mortar of the internal walls was made with clay, without the presence of lime binder, while the external wall contains a binder made of clay and lime. The sand collected near the building contains shells fragments and has features similar to the mortar aggregate found in only one of the analyzed samples. That suggests that sand from the region may have been used in at least one phase of construction.

\section{KEYWORDS}

Historical mortars. Characterization of mortars. Built heritage. 


\section{INTRODUÇÃO}

Os edifícios antigos são relatos silenciosos da evolução de uma sociedade. Ao se estudar a evolução das construções, é possível ler e aprender o que muitas vezes não foi passado para o papel, mas se mantém preservado nas paredes dos edifícios. Segundo Bazin (1983), o conjunto de conventos construído pelos franciscanos no Nordeste é uma das criações mais originais da arquitetura religiosa brasileira. Dada a grande importância dessas obras para a história do Brasil, é importante ter-se um melhor conhecimento sobre essas construções, incluindo seus componentes construtivos, especificamente as argamassas.

A identificação do material utilizado na produção de argamassas históricas pode ter três finalidades. A primeira é aprofundar o conhecimento da história e da evolução da técnica construtiva e do patrimônio arquitetônico. A segunda é identificar com mais propriedade as patologias presentes no edifício e suas possíveis causas. A terceira, uma união das demais, consiste em auxiliar na escolha do material mais adequado a ser utilizado em possíveis reparos e obras de recuperação e restauro, sem levar a degradações mais intensas nas construções.

A escolha do método analítico mais adequado depende dos objetivos práticos da caracterização, que podem ser manutenção, consolidação, reparação ou substituição (SILVA, 2002). O importante na caracterização 
de argamassas é realizar ensaios cujos resultados forneçam dados que se complementem. Algumas técnicas analíticas comumente utilizadas na geologia podem auxiliar na caracterização qualitativa e quantitativa de alguns aspectos das argamassas históricas. A difração de raios X apresenta dados sobre a mineralogia; as análises por fluorescência de raios $\mathrm{X}$ e termogravimetria fornecem dados sobre a composição; e as análises aos microscópios óptico e eletrônico são importantes para obter informações sobre a microestrutura e sobre a forma como as diferentes fases mineralógicas estão presentes, além de identificar a presença de materiais secundários. Segundo Moropoulou e Polikreti (2009), a conservação de monumentos desenvolve-se em um campo de interdisciplinaridade científica no qual a demanda por informações quantificadas e com valores de precisão e confiabilidade tem sido cada vez maior.

Este trabalho é parte integrante de um projeto em que foram estudados os conventos franciscanos presentes nos municípios de Paudalho, Recife, Ipojuca e Sirinhaém, todos no estado de Pernambuco, com o intuito de se caracterizar as argamassas de assentamento desses edifícios (SOUZA, 2011; SOUZA, CARNEIRO, 2013). O Mosteirinho da Irmandade de São Francisco, em Paudalho, atualmente está abandonado, mas como em sua origem pertenceu à Ordem Franciscana, foi incluído neste projeto. Os objetivos deste trabalho foram:

- caracterizar diferentes tipos de argamassas encontrados no Mosteirinho da Irmandade de São Francisco;

- caracterizar sedimentos do rio próximo ao objeto de estudo;

- comparar os resultados das análises dos diferentes tipos de argamassa encontrados;

- comparar os resultados de caracterização da argamassa e do sedimento fluvial;

- determinar a origem do agregado;

- determinar o tipo de aglomerante usado na mistura.

Este trabalho é um exemplo de como o conhecimento geológico pode contribuir para os estudos de conservação do patrimônio construído, juntando-se às demais áreas do conhecimento como Engenharia Civil, Química, História e Arquitetura. A identificação do material usado em argamassas históricas leva a uma maior compreensão da evolução das técnicas 
construtivas e do patrimônio arquitetônico e pode auxiliar na escolha dos materiais adequados no caso de uma possível obra de recuperação ou restauração, prevenindo danos à obra.

\section{MOSTEIRINHO DA IRMANDADE DE SÃO FRANCISCO - PAUDALHO}

Registros afirmam que a Ordem Franciscana chegou a Paudalho no ano de 1635, durante as invasões holandesas, para abrigar os religiosos franciscanos que fugiam de Olinda, Recife e outras regiões de Pernambuco. Apesar de ter sido um convento franciscano, a construção é chamada de Mosteirinho da Irmandade de São Francisco, nomenclatura normalmente utilizada para outras ordens, como a dos beneditinos. O equívoco deve ter se originado porque, na época, existia nas proximidades um engenho da Ordem Beneditina. Não se sabe precisamente a data de construção do atual prédio da igreja (Figura 1). Segundo Bazin (1983), o templo é todo edificado de tijolo cozido, material que começou a ser utilizado em Pernambuco em 1680. Entretanto, durante a realização desta pesquisa, além de parede de tijolos foi identificada a presença de paredes de pedra, o que pode indicar a utilização desse material em um primeiro momento. O edifício entrou na lista de bens tombados pelo Instituto do Patrimônio Histórico e Artístico Nacional (Iphan) em 1966, quando teve início a recuperação de sua cobertura, mas o restauro não teve continuidade (Figura 2).

FIGURA 1

Mosteirinho da Irmandade de São Francisco, Paudalho. Fotografia: Marília Lopes de Souza.

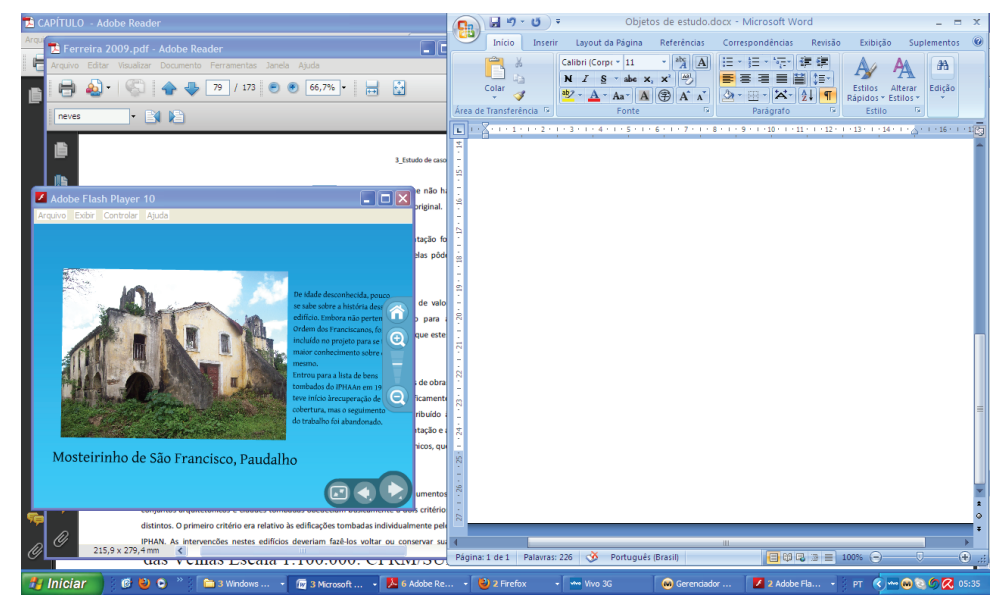


Obras abandonadas de restauração da cobertura na igreja do Mosteirinho da Irmandade de São Francisco. Fotografia: Marília Lopes de Souza.

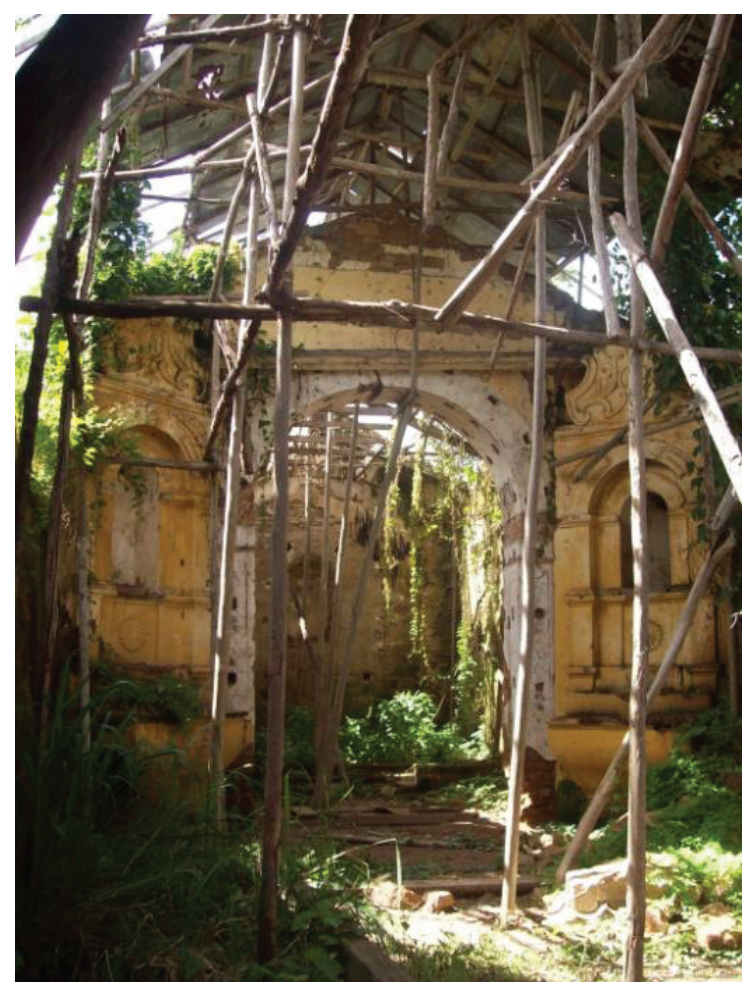

Os prédios dos conventos franciscanos do estado de Pernambuco são datados do século XVII, mas passaram por reformas posteriores. A organi-

FIGURA 3

Planta aproximada do convento de

Olinda, comum à maioria dos conventos Franciscanos. (a) Igreja conventual; (b) capela dos terceiros:

(c) campanário; (d) coro; (e) sacristia dos terceiros; (f) claustro;

(g) portaria; (h)

bloco contendo as

celas no pavimento superior; (i) sala capitular; (j) refeitório; (k) cisterna coberta por um terraço; (I) relógio de sol; (m) poços. BAZIN, Germain. A arquitetura religiosa barroca no Brasil. Trad. Glória

Lúcia Nunes. Rio de Janeiro: Record, 1983 , v. 1 , p. 142 zação espacial dos edifícios costuma ser muito semelhante nos conventos franciscanos do Nordeste, como pode ser observado em Olinda (Figura 3), João Pessoa, Sirinhaém, Recife, Igarassu e Ipojuca.

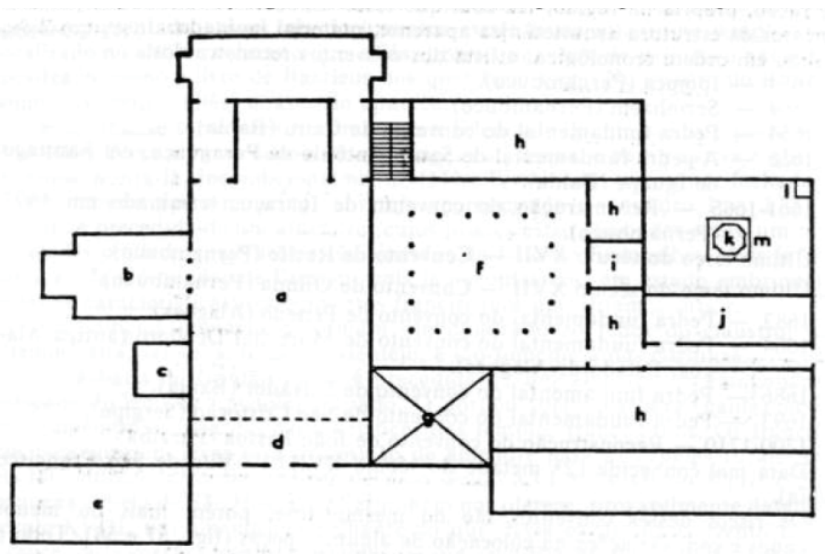


Na planta mais comum, o prédio dos conventos forma um quadrilátero em torno de um claustro, e de um dos lados fica a igreja (Figura 3). Em Sirinhaém a igreja fica à esquerda, e em Ipojuca, à direita. Em Recife, o claustro fica à esquerda, mas há um segundo claustro à direita da igreja. No andar térreo, em torno do claustro, costuma haver diversas salas (sala de leitura, refeitório, sala capitular), e no piso superior ficam os dormitórios. $\mathrm{O}$ Mosteirinho de Paudalho, no entanto, não possui as mesmas características. O edifício é formado pela igreja e dois corredores laterais com bancos de pedra, abertos para a parte externa e cobertos por um segundo pavimento, onde se encontravam os alojamentos (Figura 4).

FIGURA 4

Planta aproximada do Mosteirinho da Irmandade de São Francisco em Pauda-

Iho: (a) sacristia; (b) capela; (c) nave; (d) galeria. BAZIN, Germain. A arquitetura religiosa barroca no Brasil. Trad. Glória Lúcia Nunes. Rio de Janeiro: Record 1983, v. 1, p. 131

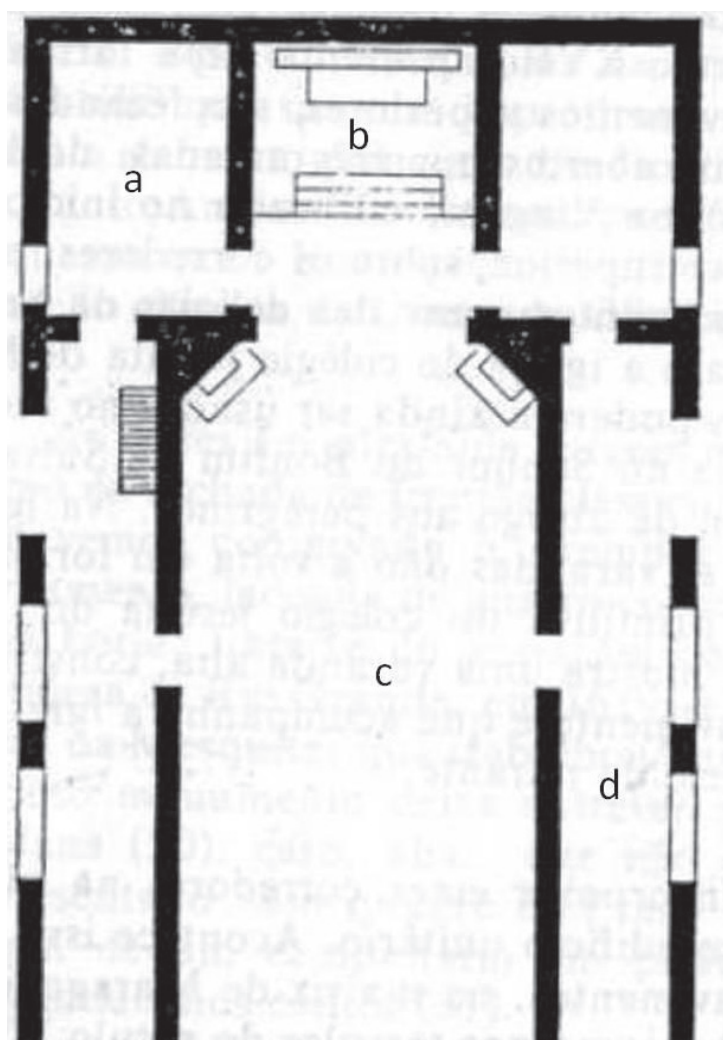

Quanto ao tipo de material utilizado na construção, segundo Katinsky (1976), no período colonial, os edifícios públicos, igrejas e residências urbanas do litoral utilizavam alvenaria de pedra e revestimento de argamassa 
à base de areia e cal. Segundo esse autor, havia casas urbanas e engenhos do nordeste construídos com tijolos desde o século XVI, e de acordo com Bazin (1983), os tijolos cozidos começaram a ser utilizados em Pernambuco no século XVII. Na igreja do Mosteirinho de Paudalho foram encontradas paredes com alvenaria de tijolos e também de pedra, diferentemente dos demais conventos franciscanos do estado, em que se observa que as paredes foram confeccionadas com tijolos cozidos.

\section{MATERIAIS}

Para a realização desta pesquisa foram coletadas amostras de argamassa do objeto de estudo, buscando abranger os diferentes tipos de argamassa de assentamento encontrados no edifício. O trabalho de coleta foi realizado por uma equipe multidisciplinar formada por profissionais de Arqueologia, Arquitetura, Geologia e Restauração. O material foi retirado de pontos mais representativos, e foram tomados os devidos cuidados para evitar que as amostras coletadas estivessem contaminadas por vegetação ou demais materiais que pudessem interferir nos resultados. A coleta foi realizada com auxílio de talhadeira e marreta, e as amostras foram armazenadas em recipientes plásticos devidamente identificados.

Foram coletadas amostras de assentamento de duas paredes da igreja, sendo uma delas de pedra em blocos irregulares (PD 02) e a outra de tijolos (PD 03). A terceira amostra foi coletada na parede do arco do corredor ao lado da igreja (PD o6), composta de blocos regulares de pedra.

Para esse estudo foram coletadas ainda duas amostras de areia em pontos próximos ao objeto de estudo. As amostras foram coletadas às margens do rio, onde a população local extrai areia com pequenos barcos areeiros (Figura 5). As amostras de areia foram submetidas a ensaios de granulometria e classificação petrográfica dos grãos, seguindo a mesma metodologia utilizada para as amostras de argamassa desagregada. Foram realizadas ainda análises complementares de microscopia óptica. 


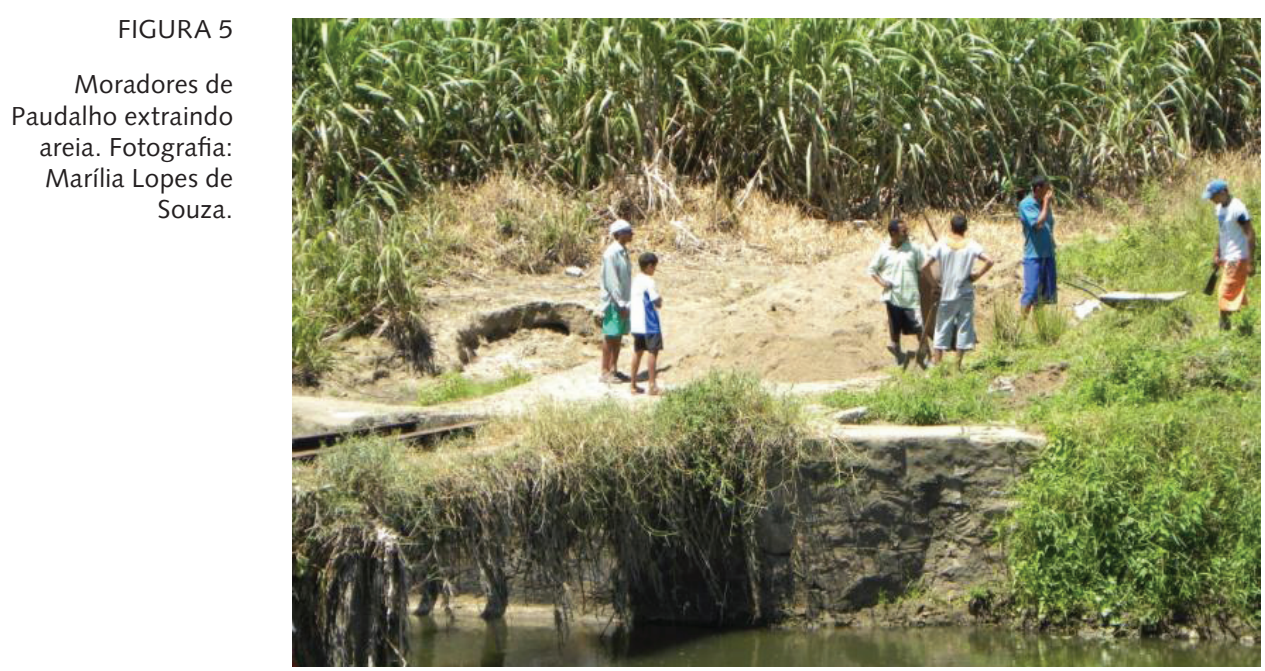

\section{MÉTODOS}

\section{Preparação das amostras}

As amostras coletadas foram submetidas a ensaios de granulometria, classificação petrográfica dos grãos ao estereomicroscópio, espectroscopia por fluorescência de raios $\mathrm{X}$, difratometria de raios $\mathrm{X}$, análises térmicas, microscopia óptica e microscopia eletrônica de varredura. O Quadro 1 apresenta os ensaios a que foram submetidas cada uma das amostras de argamassa. Como se pode notar, as amostras não foram todas submetidas à mesma sequência de ensaios, pois, para preservar a originalidade dos edifícios, apenas uma pequena quantidade de material foi coletada.

\begin{tabular}{|c|c|c|c|c|c|c|c|}
\hline \multirow{2}{*}{ Amostra } & \multicolumn{7}{|c|}{ Análise realizada } \\
\hline & DG & $\mathrm{CP}$ & ATD/ ATG & FRX & DRX & MO & MEV \\
\hline \multicolumn{8}{|l|}{ PD 02} \\
\hline \multicolumn{8}{|l|}{ PD 03} \\
\hline \multicolumn{8}{|l|}{ PD 06} \\
\hline $\begin{array}{r}\text { DG - Dis } \\
\text { ATG - Análi }\end{array}$ & $\begin{array}{l}\text { ão gr } \\
\text { mogra } \\
\text { Mic }\end{array}$ & $\begin{array}{l}\text { étrica } \\
\text { ca; AC } \\
\text { á ópti }\end{array}$ & $\begin{array}{l}\text { - Classificaç } \\
\text { =luorescência } \\
\text { MEV - Micro }\end{array}$ & $\begin{array}{l}\text { petrog } \\
\text { Raios } \\
\text { pia ele }\end{array}$ & $\begin{array}{l}\text { ATD - } \\
X-\text { Dif } \\
\text { a de va }\end{array}$ & $\begin{array}{l}\text { e term } \\
\text { etria de } \\
\text { a. }\end{array}$ & $\begin{array}{l}\text { encial; } \\
\text { X; MO - }\end{array}$ \\
\hline
\end{tabular}

Após o registro fotográfico, as amostras foram observadas primeiramente a olho nu para descrição da coloração, de acordo com a tabela de cores de Munsell (1975), textura, estrutura e tamanho do agregado (Quadro 2).

A partir de fragmentos das amostras, foram confeccionadas seções delgadas analisadas ao microscópio óptico para observação dos aspectos 
da argamassa, tais como mineralogia, estrutura, tamanho dos grãos, além de forma e tamanho dos vazios.

O material restante das amostras foi desagregado com auxílio de almofariz de ágata e pistilo de borracha (Figura 6), e, em seguida, realizou-se a separação granulométrica do material utilizando-se a sequência de peneiras nas frações de 2,4 mm; 1,2 mm; 0,6 mm; 0,3 mm; 0,15 mm e 0,075 $\mathrm{mm}$ (Figura 7). Optou-se por não realizar ataque químico nas amostras nem análise química por via úmida, uma vez que os possíveis fragmentos de concha identificados nas amostras também seriam dissolvidos pelo ataque, como lembrado por Veiga et al. (2004).

QUADRO 2

Descrição macroscópica das amostras de argamassa.

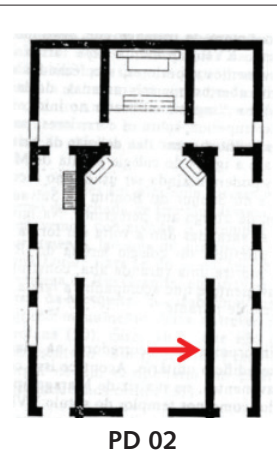

PD 02

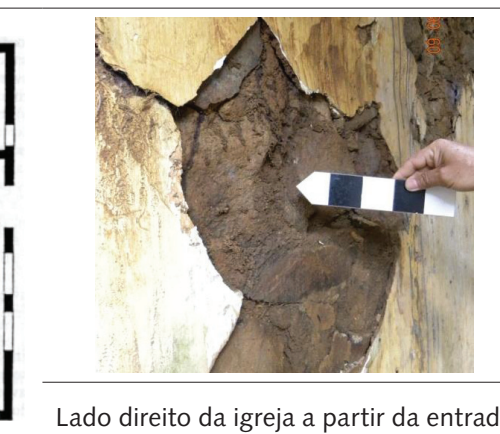
Argamassa de assentamento de pedra.

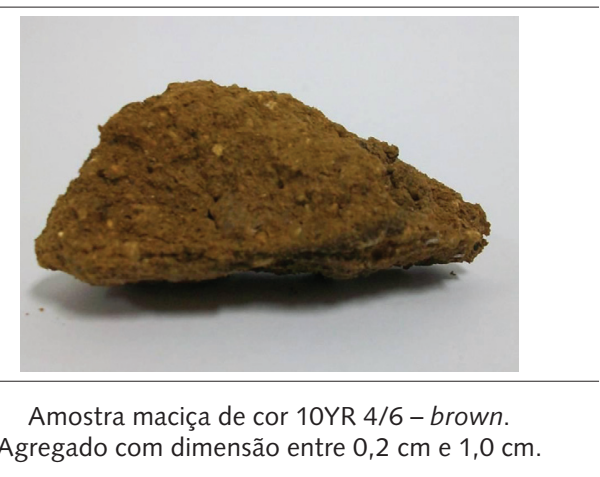

Agregado com dimensão entre $0,2 \mathrm{~cm}$ e 1,0 cm.

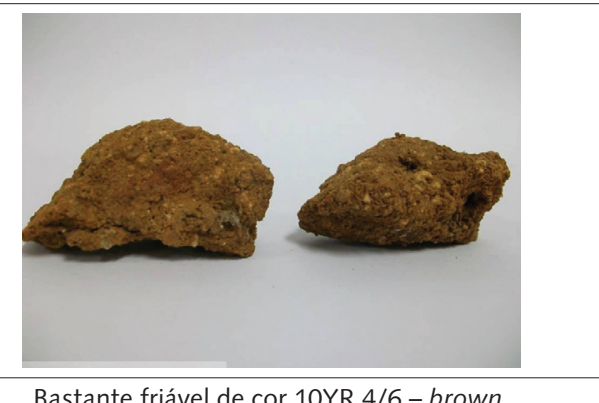

Bastante friável de cor 10YR 4/6 - brown. Agregado com dimensão predominante entre $0,2 \mathrm{~cm}$ $0,5 \mathrm{~cm}$. Fragmentos de tijolos. Ação biológica intensa. Argamassa de assentamento de tijolo

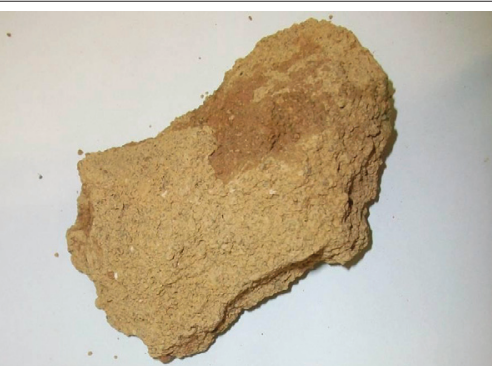

Argamassa bastante desagregada. Pasta endurecida heterogênea. Cor entre 10YR 6/6 - bright brown e 10YR $5 / 6-$ yellowish brown. Agregado com dimensão entre $0,1 \mathrm{~cm}$ e 0,3 cm. Fragmentos de rocha de até $2 \mathrm{~cm}$ de rocha granítica bastante alterada. Ação biológica intensa. 
Cada uma das frações foi analisada ao estereomicroscópio quanto à composição petrográfica. A fração passante na peneira de o,075 mm, que contém a fração predominante de pasta endurecida de argamassa, foi submetida à análise por espectroscopia por fluorescência de raios X para determinação da composição química, à difração de raios X para determinação mineralógica, e às análises termogravimétricas para determinar o teor de cal.

FIGURA 6

Material utilizado para preparação das amostras. Fotografia:

Marília Lopes de Souza.

FIGURA 7

Sequência de peneiras utilizadas. Fotografia: Marília Lopes de Souza
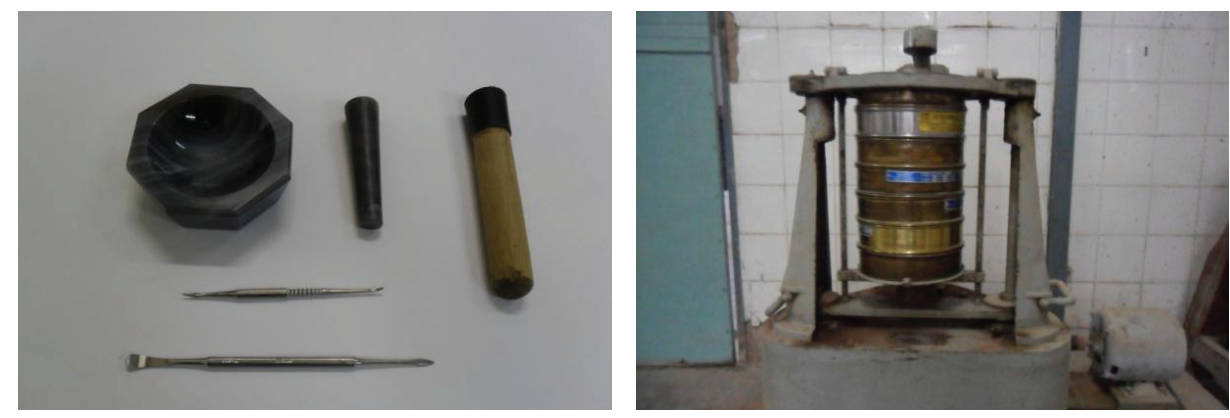

\section{Classificação petrográfica dos grãos}

A classificação petrográfica buscou identificar a natureza dos grãos, sua mineralogia, forma, cor, grau de arredondamento e esfericidade dos grãos conforme descrito por Powers em 1953 (apud SCHOLLE, 1979) (Figura 8). Foi feita a contagem de pelo menos 200 grãos para cada uma das frações granulométricas, com o auxílio de um estereomicroscópio com aumentos entre 7,5x e 34x (Figura 9).

FIGURA 8

Estereomicroscópio. Fotografia: Marília Lopes de Souza.

FIGURA 9

Análise de grãos de agregado sob lupa binocular. Fotografia: Marília Lopes de Souza.
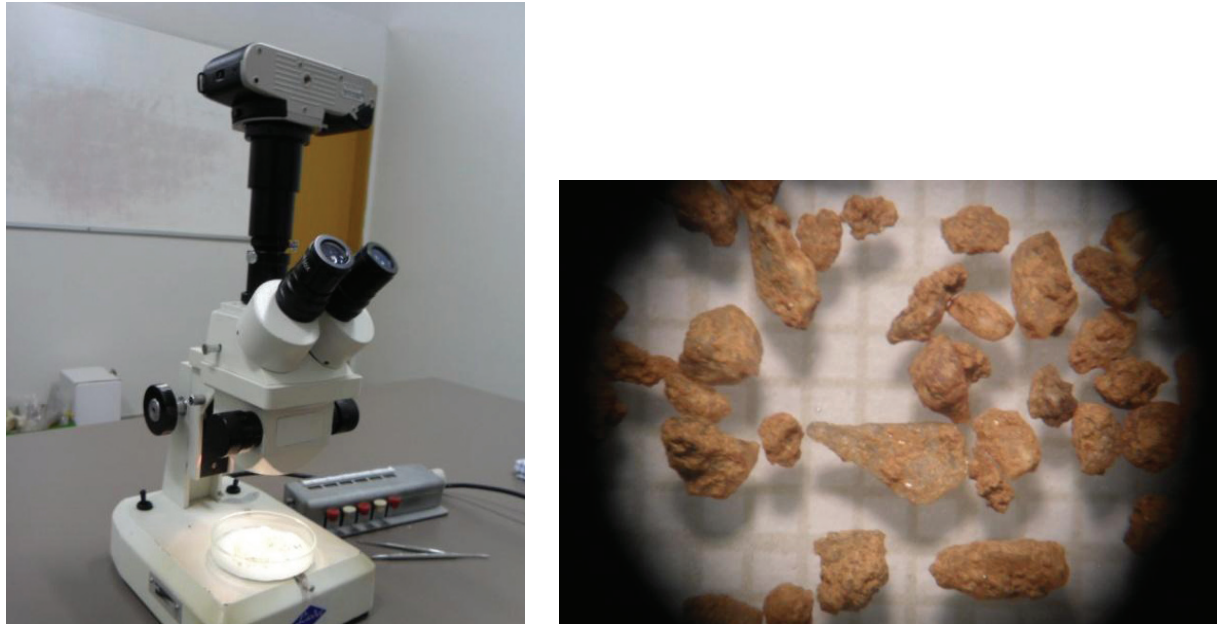


\section{Microscopia óptica}

A análise por microscopia óptica consiste na análise de lâminas delgadas das amostras, com espessura de $30 \mu \mathrm{m}$, em microscópio petrográfico de luz transmitida, com aumento de 40x a 400x.

Nos microscópios de luz transmitida, a luz atravessa o material estudado antes de atingir a lente objetiva. O microscópio petrográfico de luz transmitida difere de microscópios ópticos comuns por possuir dois polarizadores, o primeiro entre a fonte de luz e a amostra analisada, e o segundo entre a amostra e a lente objetiva. Essa organização do microscópio permite não apenas um aumento da imagem, mas principalmente uma análise das propriedades ópticas de refração características de cada mineral.

Para a confecção das seções delgadas (Figura 10), algumas amostras de argamassa foram impregnadas em resina com corante azul para facilitar a observação da forma e tamanho de poros e microfissuras. As amostras também foram analisadas quanto à mineralogia, forma e tamanho dos grãos e presença de minerais secundários.

As análises foram realizadas utilizando microscópio Leica, modelo Leiz Laborlux 11 pol., com aumentos de 40x a 400x, do Laboratório de Microscopia da Faculdade de Geologia do Centro de Tecnologia e Geociências da Universidade Estadual de Pernambuco (CTG-UFPE) (Figura 11).
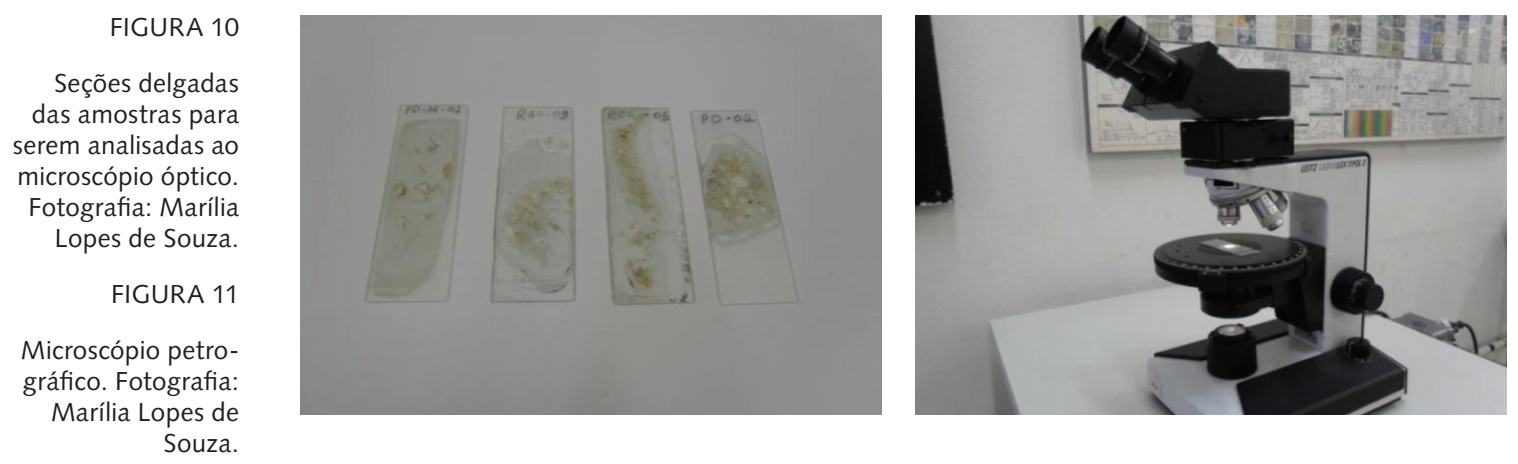

\section{Microscopia eletrônica de varredura}

A microscopia eletrônica de varredura consiste na irradiação de um feixe de elétrons sobre a amostra em estudo. A interação do feixe de elétrons com a superfície da amostra produz elétrons e fótons que emitem sinais coletados 
por detectores e convertidos em sinal de vídeo, permitindo a observação. Diferentes sinais podem ser emitidos pela interação da amostra com o feixe de elétrons, gerando diferentes imagens. Os sinais mais utilizados são os originários dos elétrons secundários e dos elétrons retroespalhados. A imagem gerada pelos elétrons secundários apresenta um contraste de relevo e de textura, sendo possível analisar as características da superfície da amostra. As imagens geradas pelos elétrons retroespalhados apresentam um contraste tanto em função do número atômico médio dos elementos presentes na amostra (imagem de composição) quanto em função do relevo (imagem topográfica). A amostra bombardeada pelo feixe de elétrons emite raios $\mathrm{X}$ característicos, que, através de seu espectro, podem ser utilizados para identificar o elemento que está emitindo a radiação. Existem dois tipos de detectores que captam os raios X: por dispersão de energia (EDS) e por dispersão em comprimento de onda (WDS), sendo o EDS mais comum. As amostras são preparadas com recobrimento por material condutor de eletricidade, tais como carbono $(\mathrm{C})$, ouro $(\mathrm{Au})$, platina $(\mathrm{Pt})$, entre outros. Isso faz que as amostras se tornem condutoras e apresentem melhores imagens, uma vez que a camada depositada é mais condutora de corrente elétrica do que a amostra, melhorando o nível do sinal (DEDAVID, 2007).

A amostra analisada neste estudo foi recoberta com ouro (Figura 12), e os ensaios de MEV foram conduzidos no Laboratório de Microscopia do Departamento de Física da UFPE (Figura 13).
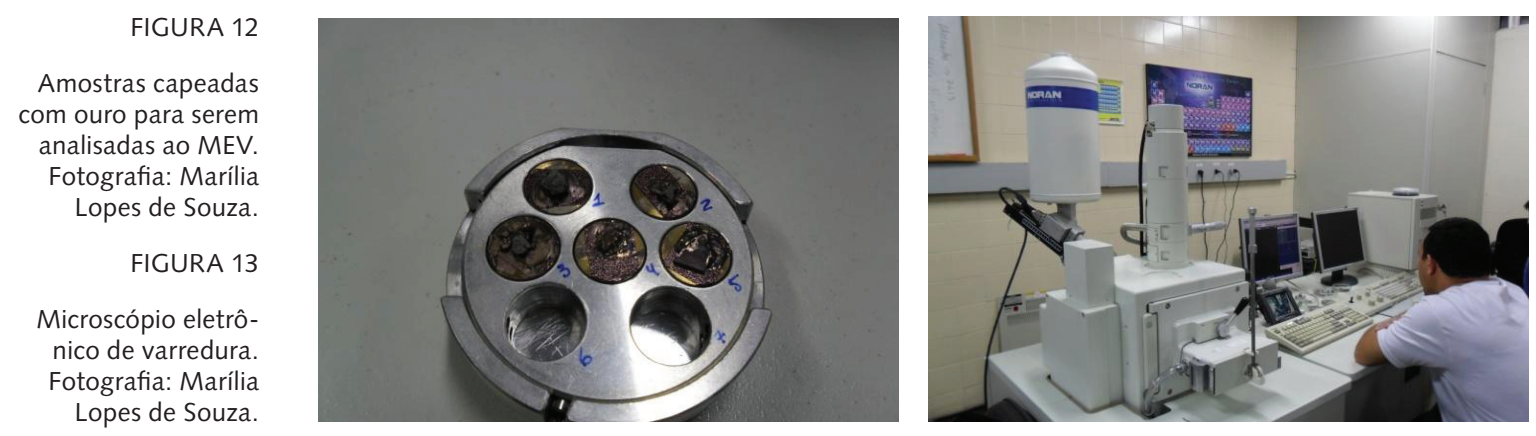

\section{Difratometria de raios $X$}

A difratometria de raios X é utilizada na identificação das fases cristalinas. Os minerais possuem planos cristalinos característicos, separados por 
distâncias da mesma ordem de grandeza dos comprimentos de onda dos raios X. Durante a análise, o mineral recebe um feixe de raios $\mathrm{X}$ que sofre difração ao atingir a amostra (ALBERS et al., 2002).

No ensaio realizado, a amostra em forma de pó é colocada sobre um porta-amostras plano, que gira em torno de um eixo, enquanto o feixe de raios $\mathrm{X}$ incide sobre o material (VEIGA et al., 2004). O resultado da análise é um difratograma, e a identificação das fases presentes é baseada na comparação do difratograma obtido com uma base de dados de um conjunto de difração padrão coletado e mantido pelo Joint Committee on Powder Diffraction Standards (JCPDS) (PICCOLI et al., 2006).

As análises foram realizadas no difratômetro Shimadzu modelo XRD7000 do Laboratório de Materiais Avançados (LMA) do Departamento de Física da UFPE. Utilizou-se a Ka do cobre $(\mathrm{Cu})$ produzida por um tubo de raios $\mathrm{X}$ com as seguintes condições de ensaio: varrimento entre $5^{\circ}$ e $70^{\circ}$ $2 \theta$, velocidade de varrimento de $0,05^{\circ} 1 \theta / \mathrm{s}$; tensão e corrente de filamento, respectivamente, de $40 \mathrm{KV}$ e $30 \mathrm{~mA}$ (Figuras 14 e 15).
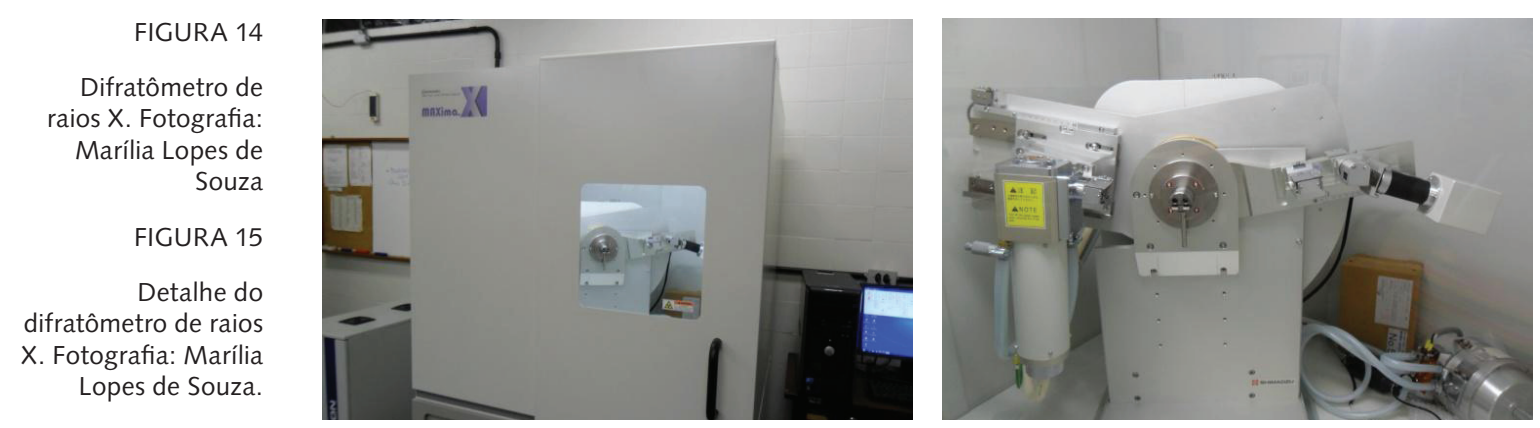

\section{Fluorescência de raios $X$}

A análise química foi realizada por meio de espectroscopia por fluorescência de raios $\mathrm{X}$, método que permite a análise qualitativa e quantitativa da composição química das amostras. A técnica consiste na incidência de um feixe de raios $\mathrm{X}$, que faz com que elétrons da camada mais próximas ao núcleo atômico sejam deslocados e substituídos por elétrons das camadas mais externas. Como resultado, é produzida uma radiação secundária fluorescente, característica de cada elemento, que pode ser, então, identificado e quantificado (GOMES, 1984). 
Para a realização do ensaio, o material peneirado com dimensão menor que $0,075 \mathrm{~mm}$ secou em estufa a $110{ }^{\circ} \mathrm{C}$, e então foram confeccionadas pastilhas utilizando-se uma prensa hidráulica a 25 ton de força. A análise química foi realizada no Núcleo de Estudos Geoquímicos e Laboratório de Isótopos Estáveis (NEG-LABISE) do Departamento de Geologia do CTG-UFPE, com espectrômetro de fluorescência de raios X Rigaku modelo RIX 3000 equipado com tubo de Rh.

\section{Análises termogravimétricas}

As análises térmicas são técnicas analíticas que permitem medir variações em propriedades físicas do material estudado em função da temperatura, que varia de acordo com um programa controlado (IONASHIRO, 2004). A análise termogravimétrica detecta mudanças de massa de um material com o aumento da temperatura. Por meio dos resultados é possível identificar as temperaturas em que ocorreram as reações que levaram às mudanças de massa e identificar reações exotérmicas ou endotérmicas, mesmo quando não há variação de massa. Os ensaios foram realizados no laboratório do Grupo de Tecnologia Mineral (GTM-DEMINAS) do CTG-UFPE, utilizando equipamento de Sistema de Análise Térmica Modelo RB-30oo-20, fabricado pela BP Engenharia (Figura 16).

FIGURA 16

Sistema de análise térmica. Fotografia: Marília Lopes de

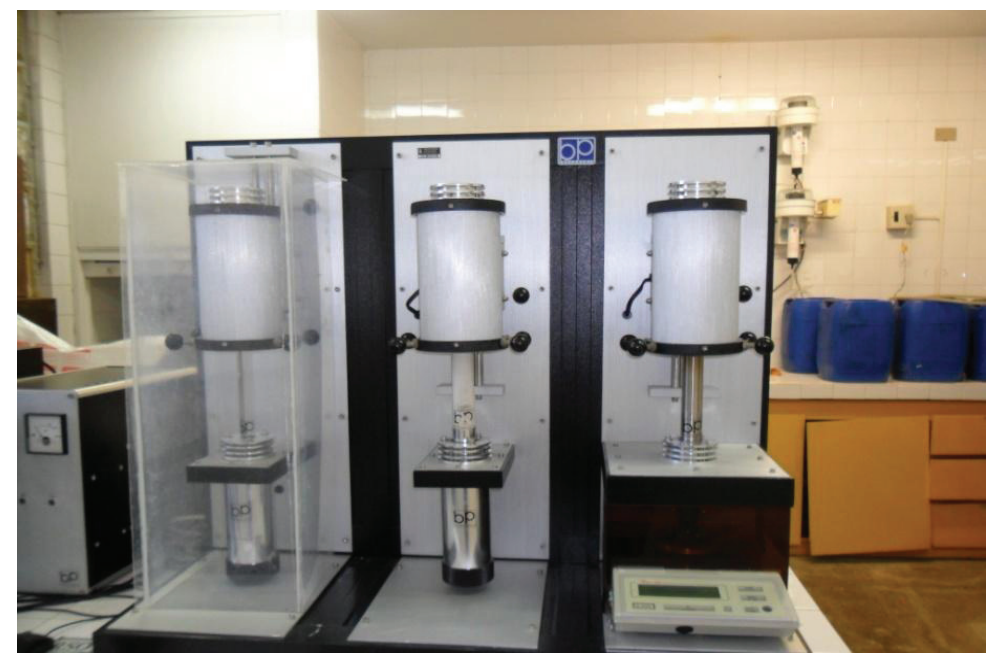




\section{RESULTADOS}

As três amostras de argamassa (PD 02, PD o3 e PD o6) apresentaram curvas de distribuição granulométrica muito semelhantes (Figura 17), indicando a utilização de areias com granulometria contínua na sua produção. Por outro lado, as duas amostras de areia de rio apresentaram granulometria mais uniforme, mas muito diferentes entre si. A amostra PD AR o1 possui menor teor de grãos com diâmetro menor que $0,3 \mathrm{~mm}$, já a amostra PD AR 02 possui maior quantidade de material fino. Isso indica que, apesar de essas duas amostras terem sido coletadas do mesmo ponto de extração, os dois tipos de areia foram retirados do fundo do rio em momentos diferentes, sendo a areia referente à amostra PD AR 02 retirada em época de cheia do rio, em que a quantidade de material fino sedimentado é maior.

FIGURA 17

Distribuição granulométrica das amostras de areia

e de argamassa desagregada.

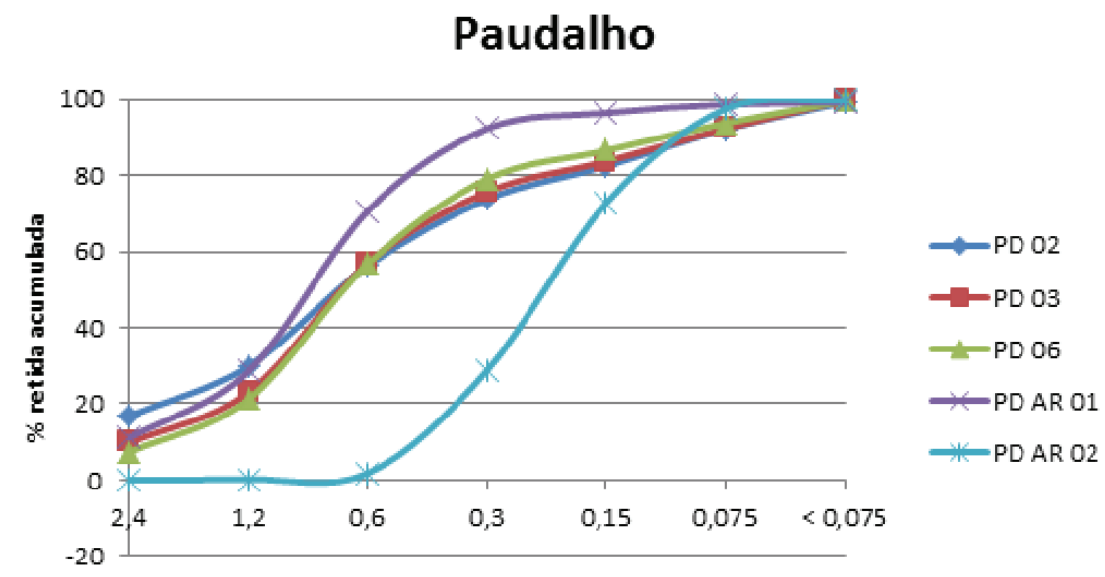

A classificação petrográfica dos grãos de agregado das amostras de argamassa apresentou grãos com grau de esfericidade alta e grau de arredondamento variando de arredondado a subangular. A composição das três amostras é bastante semelhante, com predominância de quartzo, feldspato e fragmentos rochosos em todas as amostras. Nas amostras PD 03 e PD o6 foram identificados também fragmentos de tijolo, o que se deve provavelmente à contaminação da argamassa pelo material da parede. Isso indica a presença de tijolos entre os blocos regulares de pedra na parede da galeria externa (PD 06). Na amostra PD 02 não foram identificados fragmentos de tijolo. As amostras de areia apresentaram composições bastante 
distintas. A amostra PD AR o1 possui conchas, principalmente nas frações mais grossas, mas esse material não foi identificado na amostra PD AR 02, que apresenta predominância das frações granulométricas mais finas, como pode ser observado nas fichas de caracterização petrográfica das areias apresentadas na Tabela 1.

TABELA 1

Classificação petrográfica das amostras de areia PD AR $01 \mathrm{e}$ PD AR 02.

\begin{tabular}{|c|c|c|c|c|c|c|c|c|c|c|}
\hline \multicolumn{11}{|c|}{ Amostra PD AR 01} \\
\hline & \multicolumn{2}{|c|}{$\begin{array}{c}\text { Fração } 2,4 \\
\mathrm{~mm}\end{array}$} & \multicolumn{2}{|c|}{$\begin{array}{c}\text { Fração } 1,2 \\
\mathrm{~mm}\end{array}$} & \multicolumn{2}{|c|}{$\begin{array}{c}\text { Fração } 0,6 \\
\mathrm{~mm}\end{array}$} & \multicolumn{2}{|c|}{$\begin{array}{c}\text { Fração } 0,3 \\
\mathrm{~mm}\end{array}$} & \multicolumn{2}{|c|}{$\begin{array}{l}\text { Fração 0,15 } \\
\text { mm }\end{array}$} \\
\hline $\begin{array}{l}\text { Grau de } \\
\text { esfericidade }\end{array}$ & \multicolumn{2}{|c|}{ Baixa } & \multicolumn{2}{|c|}{ Alta } & \multicolumn{2}{|c|}{ Média } & \multicolumn{2}{|c|}{ Alta } & \multicolumn{2}{|c|}{ Média } \\
\hline $\begin{array}{l}\text { Grau de } \\
\text { arredondamento }\end{array}$ & \multicolumn{2}{|c|}{ Arredondado } & \multicolumn{2}{|c|}{ Subangular } & \multicolumn{2}{|c|}{ Subangular } & \multicolumn{2}{|c|}{ Subangular } & \multicolumn{2}{|c|}{ Subangular } \\
\hline $\begin{array}{l}\text { Superfície dos } \\
\text { grãos }\end{array}$ & \multicolumn{2}{|c|}{ Rugosa } & \multicolumn{2}{|c|}{ Rugosa } & \multicolumn{2}{|c|}{ Rugosa } & \multicolumn{2}{|c|}{ Rugosa } & \multicolumn{2}{|c|}{ Rugosa } \\
\hline Mineralogia & Grãos & $\%$ & Grãos & $\%$ & Grãos & $\%$ & Grãos & $\%$ & Grãos & $\%$ \\
\hline Quartzo & 196 & 50 & 183 & 72,3 & 207 & 88,5 & 196 & 90,7 & 185 & 90,2 \\
\hline Feldspato & 73 & 18,6 & 27 & 10,7 & 12 & 5,1 & 12 & 5,6 & 3 & 1,5 \\
\hline Concha & 66 & 16,8 & 14 & 5,5 & 5 & 2,1 & & 0 & & 0 \\
\hline $\begin{array}{c}\text { Fragmento } \\
\text { rochoso alterado }\end{array}$ & 8 & 2 & 9 & 3,6 & & 0 & & 0 & & 0 \\
\hline Material argiloso & 42 & 10,7 & 20 & 7,9 & 9 & 3,8 & 8 & 3,7 & 12 & 5,9 \\
\hline Mica & & 0 & & 0 & 1 & 0,4 & & 0 & 3 & 1,5 \\
\hline Matéria orgânica & 7 & 1,8 & & 0 & & 0 & & 0 & 2 & 1 \\
\hline Total & 392 & 100 & 253 & 100 & 234 & 100 & 216 & 100 & 205 & 100 \\
\hline \multicolumn{11}{|c|}{ Amostra PD AR 02} \\
\hline & \multicolumn{2}{|c|}{$\begin{array}{c}\text { Fração } 2,4 \\
\text { mm }\end{array}$} & \multicolumn{2}{|c|}{$\begin{array}{c}\text { Fração 1,2 } \\
\text { mm }\end{array}$} & \multicolumn{2}{|c|}{$\begin{array}{l}\text { Fração 0,6 } \\
\text { mm }\end{array}$} & \multicolumn{2}{|c|}{$\begin{array}{c}\text { Fração } 0,3 \\
\text { mm }\end{array}$} & \multicolumn{2}{|c|}{$\begin{array}{c}\text { Fração } 0,15 \\
\text { mm }\end{array}$} \\
\hline $\begin{array}{l}\text { Grau de } \\
\text { esfericidade }\end{array}$ & \multicolumn{2}{|c|}{ Alta } & \multicolumn{2}{|c|}{ Alta } & \multicolumn{2}{|c|}{ Alta } & $\mathrm{Al}$ & & & \\
\hline $\begin{array}{l}\text { Grau de } \\
\text { arredondamento }\end{array}$ & Arredor & dada & Arredo & dada & Subar & sular & Suban & ular & Suba & zular \\
\hline $\begin{array}{l}\text { Superfície dos } \\
\text { grãos }\end{array}$ & Rugc & & Rug & & Rug & & Rug & & Rus & \\
\hline Mineralogia & Grãos & $\%$ & Grãos & $\%$ & Grãos & $\%$ & Grãos & $\%$ & Grãos & $\%$ \\
\hline Quartzo & & 0 & 3 & 18,8 & 174 & 85,7 & 122 & 59,5 & 180 & 89,1 \\
\hline Feldspato & 1 & 20 & 3 & 18,8 & 23 & 11,3 & 10 & 4,9 & 14 & 6,9 \\
\hline $\begin{array}{c}\text { Fragmento } \\
\text { rochoso alterado }\end{array}$ & 2 & 40 & & 0 & & 0 & 72 & 35,1 & & 0 \\
\hline Material argiloso & & 0 & 10 & 62,5 & & 0 & & 0 & & 0 \\
\hline Mica & & 0 & & 0 & & 0 & & 0 & 7 & 3,5 \\
\hline Matéria orgânica & 2 & 40 & & 0 & 6 & 3 & 1 & 0,5 & 1 & 0,5 \\
\hline Total & 5 & 100 & 16 & 100 & 203 & 100 & 205 & 100 & 202 & 100 \\
\hline
\end{tabular}


A análise da seção delgada das amostras ao microscópio petrográfico identificou uma matriz composta por biotita, muscovita e argilominerais de textura grossa na amostra PD o3, enquanto nas amostras PD o2 e PD o6 a matriz apresentou textura fina, não sendo carbonática em nenhum dos casos (Figura 18). A Figura 19 apresenta um aspecto geral da morfologia da argamassa da amostra PD o2 ao microscópio eletrônico, em que é possível observar cristais de caulinita com hábito foliado, em detalhe. Os agregados das amostras PD o3 e PD o6 são compostos por quartzo e feldspato, enquanto na amostra PD 02 foram identificados quartzo e fragmentos de rochas e conchas (Figura 18), apesar de este último material não ter sido inicialmente observado na classificação petrográfica ao estereomicroscópio.

(a)

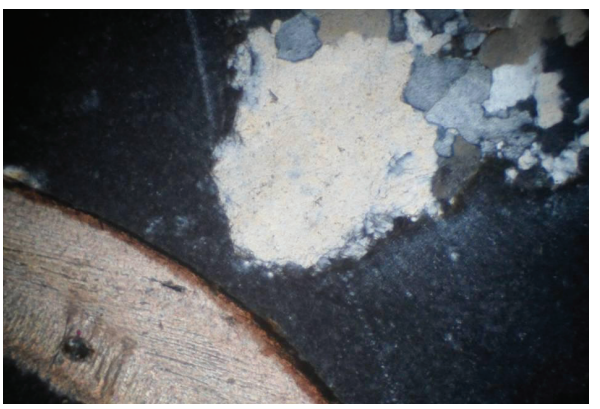

(c)

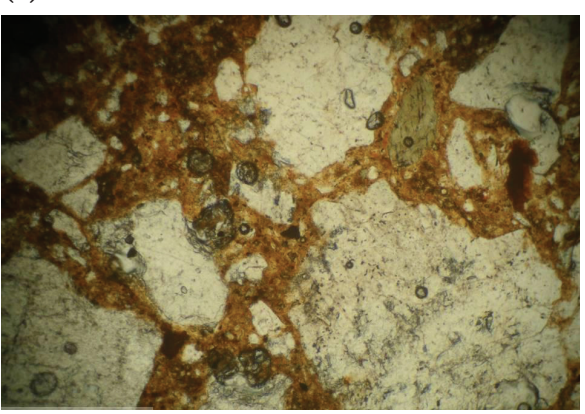

(a)

FIGURA 19

(a) Imagem da amostra PD 02 ao MEV. Hábito foliado

da caulinita; (b) Detalhe de cristal de caulinita com hábito foliado da amostra PD 02 (b)

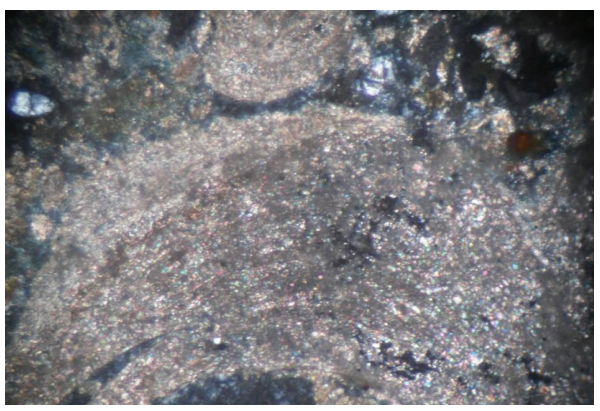

(d)

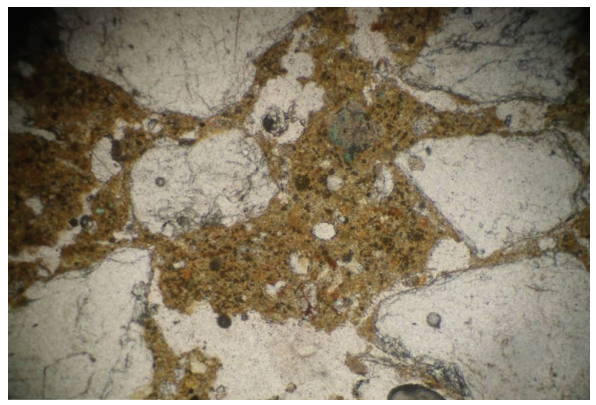

(b)

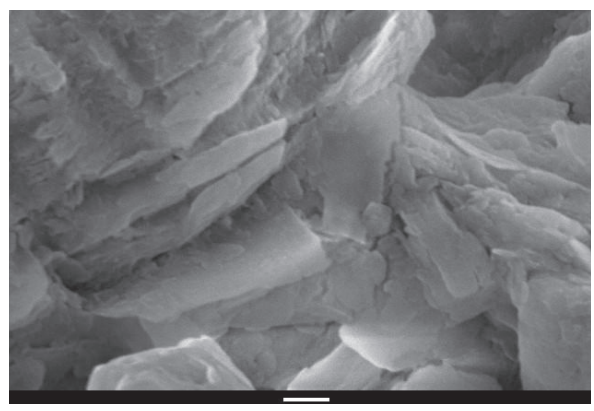


A análise química das amostras (Tabela 2) apresentou baixo teor de $\mathrm{CaO}$, uma vez que o ligante utilizado não é composto de carbonato. A análise de DRX das amostras identificou quartzo, caulinita, feldspatos e micas nas amostras. A amostra PD o6, que contém um teor de $\mathrm{CaO}$ um pouco mais elevado, apresentou pico pouco acentuado de calcita em sua análise difratométrica, indicando a presença deste mineral mesmo em pouca quantidade, apesar de ele não ter sido identificado ao microscópio (Figuras 20 a 22).

\begin{tabular}{|c|c|c|c|c|}
\hline \multirow{3}{*}{$\begin{array}{r}\text { TABELA } 2 \\
\text { Resultado da análise } \\
\text { química das amos- } \\
\text { tras de Paudalho. }\end{array}$} & \multicolumn{2}{|c|}{ PD 02} & \multirow{2}{*}{$\begin{array}{c}\text { PD } 03 \\
5,52\end{array}$} & \multirow{2}{*}{$\begin{array}{r}\text { PD } 06 \\
12,30\end{array}$} \\
\hline & $\mathrm{CaO}$ & 6,47 & & \\
\hline & $\mathrm{Al}_{2} \mathrm{O}_{3}$ & 20,90 & 21,80 & 21,40 \\
\hline & $\mathrm{Fe}_{2} \mathrm{O}_{3} \mathrm{~T}$ & 17,90 & 18,80 & 19,40 \\
\hline & $\mathrm{MgO}$ & 1,03 & 0,99 & 1,06 \\
\hline & $\mathrm{SiO}_{2}$ & 43,00 & 42,30 & 38,00 \\
\hline & $\mathrm{Na}_{2} \mathrm{O}$ & 0,27 & 0,21 & 0,07 \\
\hline & $\mathrm{K}_{2} \mathrm{O}$ & 6,22 & 5,89 & 3,97 \\
\hline & $\mathrm{TiO}_{2}$ & 1,83 & 2,04 & 2,29 \\
\hline & $\mathrm{P}_{2} \mathrm{O}_{5}$ & 0,24 & 0,34 & 0,50 \\
\hline & $\mathrm{MnO}$ & 0,41 & 0,21 & 0,13 \\
\hline & $\mathrm{SO}_{3}$ & 0,74 & 1,06 & 0,18 \\
\hline & $\mathrm{Cr}_{2} \mathrm{O}_{3}$ & 0,04 & 0,06 & 0,02 \\
\hline & $\mathrm{NiO}$ & 0,04 & 0,03 & 0,02 \\
\hline & $\mathrm{CuO}$ & 0,09 & 0,09 & 0,05 \\
\hline & $\mathrm{ZnO}$ & 0,10 & 0,08 & 0,06 \\
\hline & $\mathrm{Ga}_{2} \mathrm{O}_{3}$ & 0,01 & nd & 0,01 \\
\hline & $\mathrm{Br}$ & 0,01 & nd & nd \\
\hline & $\mathrm{Rb}_{2} \mathrm{O}$ & 0,16 & 0,05 & 0,04 \\
\hline & SrO & 0,08 & 0,08 & 0,06 \\
\hline & $\mathrm{ZrO}_{2}$ & 0,18 & 0,19 & 0,16 \\
\hline & $\mathrm{Nb}_{2} \mathrm{O}_{5}$ & 0,01 & nd & nd \\
\hline & $\mathrm{BaO}$ & 0,26 & 0,23 & 0,22 \\
\hline & $\mathrm{PbO}$ & 0,02 & 0,02 & nd \\
\hline & $\mathrm{Y}_{2} \mathrm{O}_{3}$ & nd & 0,03 & 0,03 \\
\hline & $\mathrm{As}_{2} \mathrm{O}_{3}$ & nd & nd & nd \\
\hline & $\mathrm{ThO}_{2}$ & nd & nd & nd \\
\hline & Total & 99,97 & 100,02 & 99,98 \\
\hline
\end{tabular}


FIGURA 20

Resultado da análise difratométrica da amostra PD 02

Q: Quartzo $\left(\mathrm{SiO}_{2}\right)$ K: Caulinita $\left(\mathrm{Al}_{2} \mathrm{SiO}_{5}(\mathrm{OH})_{4}\right)$; $\mathrm{Na}$ : Anortita $\left(\mathrm{CaAl}_{2} \mathrm{Si}_{2} \mathrm{O}_{8}\right)$; B: Biotita $\left(\mathrm{KFeMg}_{2}\left(\mathrm{AlSi}_{3} \mathrm{O} 10\right)(\mathrm{OH})_{2}\right)$.

FIGURA 21

Resultado da análise difratométrica da amostra PD 03.

Q: Quartzo $\left(\mathrm{SiO}_{2}\right)$;

K: Caulinita $\left(\mathrm{Al}_{2} \mathrm{SiO}_{5}(\mathrm{OH})_{4}\right)$

Mic: Microclínio $\left(\mathrm{KAISi}_{3} \mathrm{O}_{8}\right)$

Ms: Muscovita $\left(\mathrm{H}_{2} \mathrm{KAl}_{3}\left(\mathrm{SiO}_{4}\right)_{3}\right)$.

FIGURA 22

Resultado da análise difratométrica da amostra PD 06.

C: Calcita $\left(\mathrm{CaCO}_{3}\right)$;

Q: Quartzo $\left(\mathrm{SiO}_{2}\right)$;

$\mathrm{K}:$ Caulinita $\left(\mathrm{Al}_{2} \mathrm{SiO}_{5}(\mathrm{OH})_{4}\right)$;

Ab: Albita $\left(\mathrm{NaAlSi}_{3} \mathrm{O}_{8}\right)$

B: Biotita

$\left(\mathrm{KFeMg}_{2}\left(\mathrm{AlSi}_{3} \mathrm{O}_{10}\right)(\mathrm{OH})_{2}\right)$.
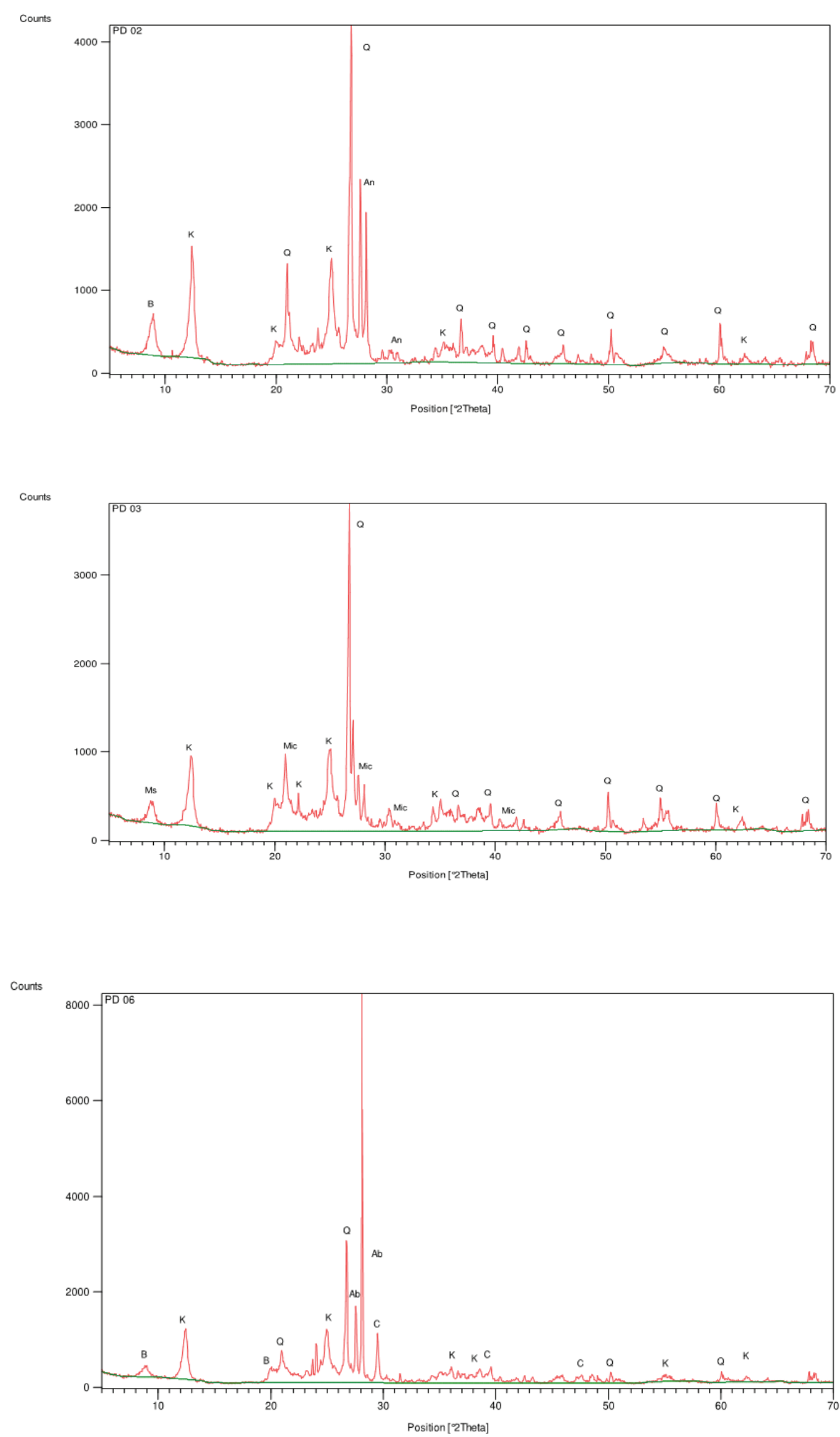

Revista CPC, São Paulo, n.19, p.164-186, jun. 2015. 
A única amostra que apresentou teor de finos em quantidade suficiente para poder realizar a análise térmica foi a amostra PD 06. A análise térmica da amostra PD o6 identificou quatro eventos térmicos (Figura 23). O primeiro, a $120^{\circ} \mathrm{C}$, corresponde à perda de água higroscópica. O pico endotérmico próximo a $525^{\circ} \mathrm{C}$ é resultado da desidroxilação da caulinita presente na amostra. Já o terceiro evento, na faixa de $825^{\circ} \mathrm{C}$, pouco acentuado, corresponde à descarbonatação da calcita, presente em pouca quantidade como indicado pelos ensaios de FRX e DRX. Por fim, a $900{ }^{\circ} \mathrm{C}$ ocorre a cristalização da mulita a partir da caulinita, representada pelo pico exotérmico na curva do gráfico de ATD.

FIGURA 23

Resultado da análise termogravimétrica da amostra PD 06

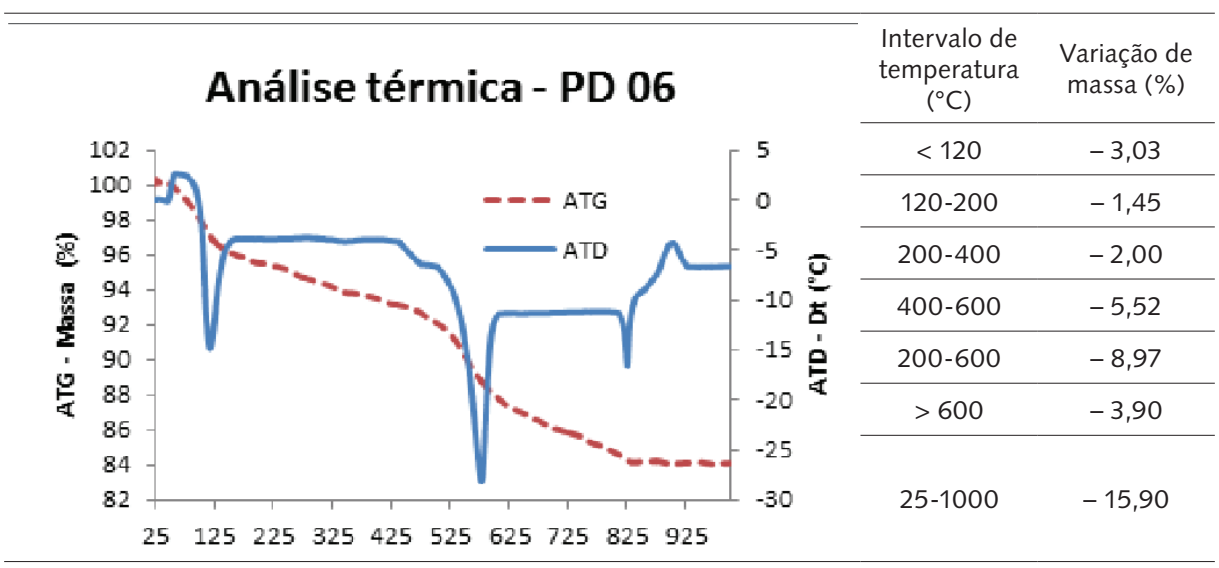

\section{CONCLUSÕES}

A partir da interpretação dos resultados das análises de distribuição granulométrica, classificação petrográfica ao estereomicroscópio, microscopia, análise química por fluorescência de raios $\mathrm{X}$, análise mineralógica por difratometria de raios $\mathrm{X}$ e análises térmicas realizadas nas diferentes amostras coletadas no edifício, foi possível chegar às seguintes conclusões.

As amostras foram coletadas de forma a abranger os diferentes tipos de argamassa de assentamento encontrados no edifício. A parede da nave foi confeccionada com pedras, e o estudo de sua argamassa (PD o2) identificou pasta de barro com fragmentos de conchas, os quais não foram identificados nas demais amostras analisadas. A amostra PD o3, coletada 
no arco-cruzeiro, também é uma argamassa de barro, mas pertence a uma parede confeccionada com tijolos. A parede da galeria externa também difere por ter sido feita utilizando-se blocos regulares de pedra, mas o estudo de sua argamassa (amostra PD o6) identificou um fragmento de tijolo, material que pode ter sido usado com as pedras. Quanto à pasta endurecida dessa amostra, foi identificada a presença moderada de calcita, o que pode indicar aglomerante misto de barro e cal em pouca quantidade (argamassa bastarda pobre em cal). Essas diferenças encontradas podem indicar etapas diferentes nas construções das paredes da nave, da galeria externa e do arco-cruzeiro.

As amostras de areia de rio possuem grande quantidade de fragmentos de concha, e esse material pode ter sido utilizado na produção da argamassa de assentamento da parede da nave (amostra PD o2). $\mathrm{O}$ fato de não terem sido detectados fragmentos de conchas nas amostras de argamassa PD 03 e PD o6 sugere que a areia do agregado possui uma fonte distinta.

Cabe ressaltar a importância da realização de diversos tipos de ensaios que, por serem complementares, são indispensáveis para uma melhor caracterização da argamassa. A investigação sistemática das argamassas históricas facilita a apresentação de resultados mais detalhados e permite a escolha de materiais mais adequados em trabalhos de recuperação.

\section{REFERÊNCIAS}

ALBERS, A. P. F. et al. Um método simples de caracterização de argilominerais por difração de raios X. Cerâmica, v. 48, nº 305, p. 34-37, jan.-fev.-mar. 2002.

BAZIN, Germain. A arquitetura religiosa barroca no Brasil. Trad. Glória Lúcia Nunes. Rio de Janeiro: Record, 1983. v.1 e 2.

DEDAVID, Berenice Anina. Microscópio eletrônico de varredura. In: DEDAVID, Berenice Anina et al. Microscopia eletrônica de varredura: aplicações e preparação de amostras: materiais poliméricos, metálicos e semicondutores. Porto Alegre: EDIPUCRS, 2007. p.9-26.

GOMES, Celso de Barros. Técnicas analíticas instrumentais aplicadas à geologia. São Paulo: Edgard Blücher, 1984 .

IONASHIRO, Massao. Giolito: fundamentos da termogravimetria e análise térmica diferencial e calorimetria exploratória diferencial. São Paulo: Giz Editorial, 2004.

KATINSKY, Julio Roberto. Um guia para a história da técnica no Brasil Colônia. São Paulo: FAU-USP, 1976. 
MOROPOULOU, Antonia; POLIKRETI, Kyriaki. Principal component analysis in monument conservation: three application examples. Journal of Cultural Heritage, v. 10, no 1, p. 73-81, 2009.

MUNSELL. Soil color charts. Baltimore: Munsell Color, 1975.

PICCOLI, R. et al. Características das principais técnicas analíticas aplicadas à caracterização de materiais. In: $17^{\circ}$ Congresso Brasileiro de Engenharia e Ciência dos Materiais - CBECiMat, 2006, Foz do Iguaçu. Anais..., Foz do Iguaçu, 2006, v. 17, p. 289-300.

SCHOLLE, Peter A. A color illustrated guide to constituents, textures, cements, and porosities of sandstones and associated rocks. Tulsa: American Association of Petroleum Geologists, 1979.

SILVA, A. S. Caracterização de argamassas antigas - casos paradigmáticos. In: Cadernos Edifícios $n^{\circ}$ 2. Lisboa: LNEC, 2002. p. 97-101.

SOUZA, Marília Lopes. Caracterização de argamassas históricas de conventos franciscanos do Estado de Pernambuco. 2011. Dissertação (Mestrado em Engenharia Civil). Programa de PósGraduação em Engenharia Civil - Universidade Federal de Pernambuco, Recife, 2011.

SOUZA, Marília Lopes; CARNEIRO, Arnaldo Manoel Pereira. Caracterização de argamassa de assentamento do Convento de Santo Antônio em Recife-PE. In: X Simpósio Brasileiro de Tecnologia de Argamassas. Fortaleza, 2013. Anais.

VEIGA, Maria do Rosário et al. Conservação e renovação de revestimentos de paredes de edifícios antigos. Lisboa: LNEC, 2004.

RECEBIDO EM: 24/03/2015

APROVADO EM: 21/05/2015

\section{MARÍLIA LOPES DE SOUZA}

Geóloga, Mestre em Engenharia Civil pela Universidade Federal de Pernambuco (UFPE). E-mail: mar.ilhals@ gmail.com.

\section{ARNALDO MANOEL PEREIRA CARNEIRO}

Engenheiro Doutor em Engenharia Civil pela Universidade de São Paulo (USP), professor do Centro de Tecnologia e Geociências da Universidade Federal de Pernambuco. E-mail: ampc@ufpe.br. 